\title{
Does Career Growth really Matter to Knowledge Employees? A Mechanism Research Exploration of Perceived Career Growth Opportunities on Turnover Intention of Knowledge Employees
}

\author{
Jin Cheng ${ }^{1, a^{*}}$, Yuqing $\mathrm{He}^{2, \mathrm{~b}}$, and Xiaoni Cheng ${ }^{3, \mathrm{c}}$ \\ ${ }^{1,2}$ School of Management, Xiamen University, Xiamen, 361005, China \\ ${ }^{3}$ School of Economics, Hebei University, Baoding, 071000, China \\ achengjin1025@xmu.edu.cn, b854917603@qq.com, c278105221@qq.com
}

\begin{abstract}
Keywords: Knowledge employees; Perceived career growth opportunities; Positive mood;
\end{abstract} Turnover intention

\begin{abstract}
The turnover behavior of knowledge employees has a great influence on the enterprises. In view of the knowledge employees' general need to pursue self-growth, this paper focuses on the relationship between perceived career growth opportunities and the turnover intention of knowledge employees. On the basis of literature review, our paper put forward the following hypotheses: perceived career growth opportunities negatively affect the turnover intention of knowledge employees; organizational commitment mediates the relationship between career growth and turnover intention and also positive mood has also been posited to moderate the relationship between organizational commitment and turnover intention.
\end{abstract}

\section{Introduction}

The turnover of knowledge employees has become an important issue for many enterprises in China. With the transformation of modern competition from monetary capital to intellectual capital, the knowledge employees have become the core strength to promote company's technological innovation, market innovation and management reform, so that their turnover can cause large tremors of an enterprise. Therefore, it is very important for the enterprise to pay attention to the issue of knowledge employees' turnover which is related to the competitive advantage and sustainable development of an enterprise.

In current studies on knowledge employees, some scholars believe that knowledge employees attach great importance to achievement and spiritual motivation, and have a strong desire for realizing self-value [1]. Tampoe (1993) indicates that: In working environment, the first four factors that knowledge employees focus on are individual growth (34\%), independence (31\%), business achievement (28\%) and wealth (7\%) [2]. Thus, for knowledge employees, comparing with wealth, they focus more on individual growth, especially professional growth. In current research on the turnover of knowledge employees, it is undertaken to study knowledge staff turnover intentions from the perspective of career growth. To fill this research gap, our paper explores impact mechanism of perceived career growth opportunities on turnover intention of knowledge employees, to enrich the study of knowledge employees' turnover intention.

\section{Literature Review}

Employee turnover refers to the course of termination employment for an individual who gets material compensation from an organization, which emphasizes the interruption of employment relationship between employees and organization [3]. In the study of employee turnover, voluntary turnover intention is the main concern for scholars. So far, there are four classical models of employee turnover: March\& Simon model, Price model, Mobley intermediary chain model and its extended intermediary chain model, as well as Steers\& Mowday (1981) model.

March and Simon (1958) coauthored the book "The Theory of Organization" and the model of employee turnover mentioned in it can be said to be the forerunner of turnover study. They lead 
labor markets and behavioral variables into staff turnover process to established a solid theoretical basis for employee turnover in the future. March and Simon believe that employee turnover depends on two factors, first is turnover intention, that means employee feels that he should leave his job and want to leave his job; Second is the possibility of turnover, that is the extent of easy turnover for employee. Only when employee wants to leave his job and actual condition allows him to leave at the same time, the action of turnover can really happen [4].

The most representative turnover research is Price's research result in 1970s. In his research, there are 6 major versions till now, and the most mature one is Price Mueller (2000) model. In Price Mueller model, the dependent variable is staff turnover intention, and the variables are environment variable, individual variable and structured variable. Moreover, it also involves mediating variable in this model. Among these variables, environment variables include opportunity variable of macro-environment and family responsibility variable of micro-environment. Individual variables contain general training, that is the degree which employee's skills and knowledge can be transferred to other units; employee participation which means the degree of willing to work for employee; employee's negative or positive emotion. Structured variables include employee's autonomy given by organization, organization's equitable distribution, employee's pressure in work, payment level, promotion opportunity, monotony of work and social support. In Price Mueller model, job satisfaction and organizational commitment are key mediating variable of expected turnover intention, and they influence employee's turnover intention by affecting job seeking behavior [5].

Mobley's (1977) intermediary chain model is another important model to explain employee's turnover. In this model, Mobley regards turnover intention as the main influence factor of turnover action, and he researches employee turnover issue by studying employee's dynamic psychological and cognitive process from dissatisfaction to actual turnover. When employee is not satisfied with his job, he is likely to be slack in work or absent from work, and he may also consider turnover. If he has the intention to resign, employee will consider the expected revenues and costs of resignation to decide whether he will have the intention to find other jobs elsewhere. If employee finds new job, he will compare the new position to the current position to determine whether to leave or not ultimately. In this model, Mobley believes that employee's job dissatisfaction does not generate turnover, only turnover intention will generate turnover action. Later, Mobley launches expanded intermediary chain model, he believes the process of employee from turnover intention to actual turnover is affected by 4 basic factors: (1) job satisfaction; (2) The earning expectation of changing jobs in enterprise; (3) The earning expectation of changing jobs out of enterprise; (4) non-work values and accidental factors [6].

Steers and Mowday (1981) model is another representative employee turnover model, this model is also in search of the relationships between main antecedents and various variables of employee turnover. According to this model, Steers and Mowday consider that the employee attitude variables including employee's job satisfaction, organizational commitment and participation are the main antecedents of employee turnover intention, and their job expectation and value of work are the main factors influencing employee attitude. Employee expectation and work value are not only under the influence of individual characteristic, but also influenced by external employees' job choices and job information they get. Organizational characteristics, organizational experience and employee performance affect the impact of work value or expectation on employees' attitudes. Apart from employee's attitude, employee's turnover is also influenced by non-work matters [7]. The most typical feature of this model is it regards employee's work value and job expectation as clear antecedents of work-related attitude, and when it checks employee's turnover intention and turnover action, external environmental factors and non-work impact will be added; Meanwhile this model gives full attention to mutual relationship between employee's efforts and subjective attitude, and believes employee's efforts can change work attitude, and attitude can also affect the level of effort.

The above are four classic models of employee voluntary turnover at present, on the basis of these models, many scholars empirically study some variables in models and explore the factors 
affecting employee's voluntary turnover. For example, Ham and Griffeth put forward gender, age, family responsibilities, job satisfaction, job expectations, material rewards, work performance and increasing work complexity, organizational incentives can affect employee's turnover [8]. Deery and Shaw argues that subordinate or poor communication among colleagues are important factors of affecting employee's turnover. Moreover, enterprise's acceptable levels towards turnover can also affect employee's turnover [9].

It can be seen from the above literature that scholars have wide vision towards research on employee's turnover, like personal factors (gender, age, level of education), work factors (work autonomy, work load), organizational factors (salary, relationship, communication culture) are all involved. About employee turnover research, scholars not only focus on micro-variables, they also take macro factors, such as employment opportunities and labor market into account. Not only consider employee turnover problem from the angle of static elements, but also from dynamic psychological, cognitive perspectives. Current research on employee turnover is quite mature, we can continue to study turnover problems of some specific fields and specific staff to enrich employee turnover research.

\section{Hypothesis Development}

The Relationship between Knowledge Employee Career Development and Turnover Intention. "Knowledge employee" this concept is first proposed by Peter F.Drucker, a famous management scientist, he defines "those who hold and use symbols and concepts and use knowledge or information to work" as knowledge employees [10]. Druker (2002) further proposes that knowledge employees are staff who have formal education, continuous knowledge acquisition and updating in a particular field and have adequate theoretical knowledge, and they will naturally treat the people within the same industry in other institutions as counterparts, instead of different people in same organization $^{[11]}$. Davenport, Robert, and Susan defines knowledge employees as all working people correlated with knowledge, including applying, creating, obtaining knowledge [12]. Schultze argues that knowledge work needs actors with feeling and thought to get the job done, and they need to be subjective and bring tacit knowledge to work [13]. Liao believe knowledge employees are those who engage in knowledge creation, knowledge application and knowledge dissemination on the basis of certain knowledge. Therefore, knowledge employees in this article are defined as staff who create value for organization and pursue personal development with their own expertise and ability [14].

In the study of knowledge employee characteristics, based on frequency statistics of knowledge employee characteristics, Liao Jianqiao et al (2009) conclude that knowledge employees are autonomous, educated, creative and they are the key wealth of organization. Meanwhile, knowledge employees conduct immaterial labor, their knowledge and skills are easily out of date, they are highly skilled towards these knowledge, and they are loyal to their occupation rather than organization [14]. Jin (2014) thinks that intellectuals have six core characteristics, namely, innovation, complexity, autonomy, loyal to occupation but not employer (commitment), valuing learning opportunities, equality requirement etc. [15]. Through these studies, we can see that valuing learning opportunities and valuing improvement of professional ability are typical characteristics of knowledge employees. This is partly because knowledge employees make a living based on knowledge and expertise, and improvement of professional skills and knowledge have decisive significance for their future lifestyle, so knowledge employees attach great importance to their "ability to be employed"; On the other hand, because knowledge employees are quite important in enterprises and they are relatively competitive in external labor market. Therefore, they need more about the requirement of being respected and self-fulfilling on the bases of basic survival and security needs. Meeting these needs can further motivate knowledge employees and mobilize enthusiasm and creativity of knowledge employees.

Graen et al(1997) put forward that career growth refers to the rate of individual flowing to his more valuable work series [16]. On this basis, Weng and $\mathrm{Hu}$ (2009) define that the so-called career growth refers to employees' career growth condition, including employees' knowledge and 
competence development, career goals and the opportunities for promotion and development within organizations [17]. Based on above descriptions of characteristics of knowledge employees, we can see perceived career growth opportunities of knowledge employees are very important for knowledge employees.

Thus, we conclude that:

Hypothesis 1: the perceived career growth opportunities of knowledge employees are negatively associated with turnover intention, that means the more knowledge employees perceive their career growth opportunities in organization, the lower their turnover intention.

The Relationship between Career Growth and Organizational Commitment. Organizational commitment refers to the level of an individual's identification with and his or her organization as well as the level of supporting and caring the development of organization. Meyer and Allen divided organizational commitment into three dimensions, affective commitment, continuous commitment and normative commitments; affective commitment is the degree of psychological identification, belief and support of employees towards organizational objectives and values; continuous commitment means the longer the employee serve in a particular organization, the greater losses will be when he leaves the organization, and that attitude makes him hard to leave the organization; and normative commitment is based on social responsibility and workplace codes, so they continue to work for organization[18].

When knowledge employees perceive there are more opportunities for career development in organization, their commitment to organization will increase. On the one hand, from the perspective of social exchange theory, organization provide more opportunities for individuals and individuals will have a deeper sense of identification and support to organization which will raise individual's affective commitment. On the other hand, when organization provides more opportunities for individuals, for individual, leaving the organization will have greater loss to individual development and that makes him more difficult to leave the organization, so individual's normative commitment will be improved.

Therefore, we assume that:

Hypothesis 2: perceived career growth opportunity of knowledge employees is positively associated with organizational commitment, that means when knowledge employees perceive more opportunities for career growth in organization, their commitment to organization is enhanced.

The Relationship between Organizational Commitment and Turnover Intention. Organizational commitment refers to the identity and belonging from individual to organization [19]. Angle and Perry point out that Organizational commitment is important decisive variable in the study of turnover [20]. Steers and Mowday (1979) find that employee's organizational commitment is obviously negatively associated with expected turnover intention ${ }^{[19]}$, and a lot of later studies have verified this. When it comes to the topic about knowledge employee turnover intention, we are also sure that the negative relationship between organizational commitment and turnover intention still exists. Therefore, we assume that:

Hypothesis 3: Organizational commitment is negatively associated with turnover intention of knowledge employee, the stronger the commitment from knowledge employees to organization, the lower the turnover intention.

On the basis of the above arguments, we come up with the following assumption:

Hypothesis 4: Organizational commitment plays a mediating role between career growth and turnover intention.

Moderating Effects of Positive Mood. Positive mood has received full attention in emotional psychology research. Many researchers begin to study the concept of positive emotion, its functions and its application in organizational life. Positive mood is a kind of good feeling of wanting to smile [21]. Fredrickson considers "positive mood is unique instant reaction to some personally meaningful things, and it is a temporary pleasure". Positive mood expansion and construction theory believe that comparing with neutral state, positive mood such as joy and satisfaction can extend individual's attention and sequence of thought ${ }^{[22]}{ }^{[23]}$. Meanwhile the extension of thought sequence with the help of positive mood can promote the resources construction within and between 
individuals, and enhance social contact, which is helpful for individuals participating in activities actively.

In this article, we believe that employees' positive mood can adjust the relationship between employee's organizational commitment and turnover intention. According to the model of mood congruency, mood can affect the subjective evaluation to social goals, and lead individual to have consistent cognition with mood information ${ }^{[24]}$ and also positive mood experience will make individuals more actively perceive of others and society events, to cause positive deviation to others or social events. When employees have positive mood, they will see themselves and organization more positively, and this view will reduce the influence of organizational commitment on employees' turnover intention. When employees feel more confident about themselves, even if employees' sense of loyalty to organization is not so high, they still believe they can achieve good results in organization, so their turnover intention will reduce. When employees can be more positive to organization, even if their emotion to organization is not so deep, they still think the organization is promising and their turnover intention will also reduce. On the contrary, when employees have more negative perception to themselves and organization, organizational commitment will have stronger influence on turnover intention.

Thus, we make the following assumption:

Hypothesis 5: Positive mood has negative moderating effect on the relationship between organizational commitment and turnover intention. When employees have more positive mood, the negative impact of organizational commitment to turnover intention weakens. On the contrary, when employees have less positive mood, the negative impact of organizational commitment to turnover intention enhances.

Based on the above basis and research hypothesis, this article establishes the following conceptual model (Fig. 1):

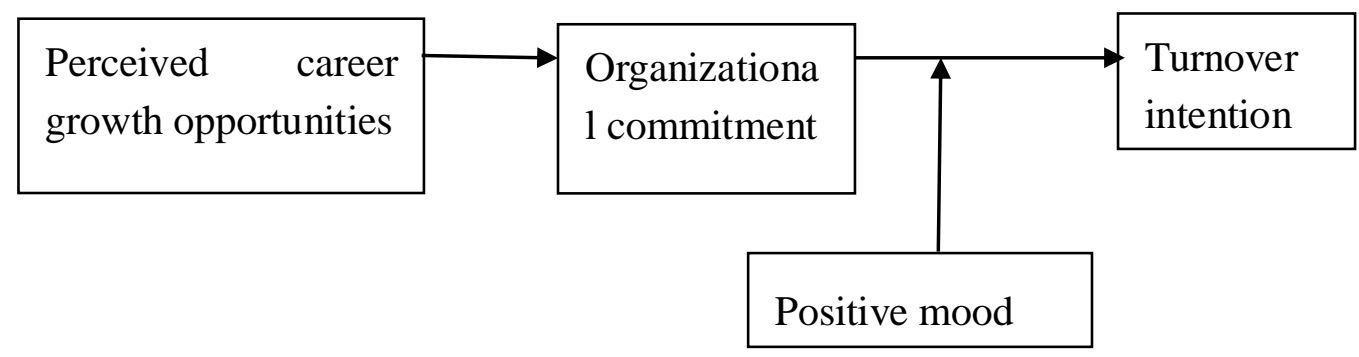

Figure 1. Knowledge employee turnover intention model based on the perspective of career development

\section{Summary}

Based on the characteristics of knowledge employees, this research posits the perceived career growth opportunities has the negative influence to knowledge employees' turnover intention, and organizational commitment mediates the relationship between career growth and turnover intention, while employees' positive mood negatively regulates the relationship of organizational commitment and turnover intention. Our paper provides a new perspective of career growth to explain the turnover intention of knowledge employee. Also our paper stresses the moderating effects of positive mood in the relationship between organizational commitment and turnover intention which deepens our understanding of the relationship between these two variables. The empirical research about these hypotheses could be conducted in the future.

\section{Acknowledgements}

This research is funded by the Natural Science Foundation of China (71302070). 


\section{References}

[1] Jiang Lin. Characteristics and Management of Knowledge Employees [J]. Economic Theory and Economic Management, 2002, 09:58-62.

[2] Tampoe M. Motivation Knowledge Workers - the challenge for the 1990s [M]. Long Range Planning, 1993.

[3] Mobley W H. Employee Turnover: Cause, Consequences, and Control [J]. Lancet, 1982, 1(8063):542-6.

[4] Macch J G \&Simon H A. Organizations [M]. New York, Wiley, 1958.

[5] Price J L. Reflection on the Determinants of Voluntary Turnover [J]. International Journal of Manpower, 2000, 22(7):600-624.

[6] Mobley W H. Intermediate Linkage in the Relationship between Job Satisfaction and Employee Turnover [J]. Journal of Applied Psychology, 1977, 62:237-240.

[7] Steers R. M., Mowday, R. T. Employee Turnover and Post-Decision Accommodation Process [J]. In: Cummings, L.L., Staw, B M., ed. Research in Organizational Behavior. Greenwich, Conn: JAI Press, 1981: 235-281.

[8] Ham P W, Grifffeth R. Employee Turnover [M]. Cincinnati Southwestern College Publishing, 1995.

[9] Deery M A, Shaw R N. An Exploratory Analysis of Turnover Culture in the Hotel Industry in Australia [J]. International Journal of Hospitality Management, 1997, 16(4):375-392.

[10]Drucker P F. The Age of Social Transformation [J]. The Atlantic Monthly, 1994, 274(5):53-80.

[11]Drucker P F. They're Not Employees, They're People [J]. Harvard Business Review. February, 2002, 70-77.

[12]Davenport T H, Robert J T, Susan C. The Mysterious Art and Science of Knowledge-Worker Performance [J]. Sloan Management Review, 2002, 44(1):23-30.

[13] Schultze U, Jr R J B. Place, Space and Knowledge Work: A Study of Outsourced Computer Systems Administrators [J]. Accounting Management \& Information Technologies, 2000, 10(3):187-219.

[14]Liao Jianqiao, Wen Peng. Definition, Characteristics and Classification of Knowledge Employees [j]. Chinese Journal of Management, 2009, 6 (2) 277-283.

[15]Jin Guorong. Discussion on Characteristics of Knowledge Employees [J]. Expert Forum, 2014, (8): 7-9.

[16]Graen, G. B., Chun, H., Dharwadkar, R. Wakabayashi, M.. Predicting Speed of Managerial Advancement Over 23 Years Using a Parametric Duration Analysis: A Test of Early Leader-Member Exchange, Early Job Performance, Early Career Success, and University Prestige. Best Papers Proceedings: Making Global Partnerships Work Association of Japanese Business Studies, 1997, 75-89.

[17]Weng Qingxiong, Hu Bei. Staff Career Development Structure and its Influence on Turnover Intention [J]. Industrial Engineering and Management, 2009 (1): 14-21.

[18]Meyer, J.P., Allen, N.J. Commitment in the Workplace [M]. Thousand Oaks, CA: Sage Publications, Inc., 1997.

[19]Mowday R, Porter L, Steer R. Employee or the Psychology of Commitment, Absenteeism and Turnover [M]. New York: Academic Press, 1979.

[20]Angle H L, Perry J L. An empirical Assessment of Organizational Commitment and Organizational Effectiveness [J]. Administrative Science Quarterly, 1981, (28):1-13. 
[21]Russell J A, Feldman B L. Core Affect, Prototypical Emotional Episodes, and Other Things Called Emotion: Dissecting the Elephant. Journal of Personality and Social Psychology, 1999, 76:805-819.

[22]Fredrickson B L. The Role of Positive Emotions in Positive Psychology: The Broaden-and Build Theory of Positive Emotions. American Psychologist, 2001, 56:218-226.

[23]Fredrickson B L, Branigan C. Positive Emotion. In: T J Mayne, G A Bonnano (Eds.), Emotions: Current Issues and Future Directions. New York, NY: The Guilford Press, 2001:123-151.

[24]Mayer J D, Gaschke Y N, Braverman D L. Mood-Congruent Judgment is A General Effect. Journal of Personality and Social Psychology, 1992, 63:119-132. 